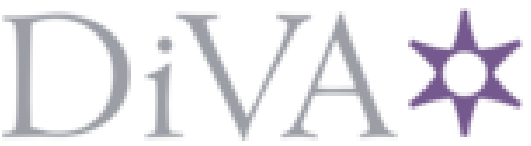

http://www.diva-portal.org

Postprint

This is the accepted version of a chapter published in Mapping Religion and Spirituality in a Postsecular World.

Citation for the original published chapter:

Frisk, L. (2012)

Religion, Spirituality and Everyday Life in Sweden

In: Giordan, Giuseppe / Paco, Enze (ed.), Mapping Religion and Spirituality in a

Postsecular World Leiden, Boston: Brill Academic Publishers

Religion and the Social Order

N.B. When citing this work, cite the original published chapter.

Permanent link to this version:

http://urn.kb.se/resolve?urn=urn:nbn:se:du-5396 


\title{
RELIGION, SPIRITUALITY, AND EVERYDAY LIFE IN SWEDEN
}

\author{
Liselotte Frisk, Dalarna University
}

\section{Introduction}

The focus of this paper is the concept of "spirituality" and its use and meaning in different contexts in contemporary Sweden. Themes highlighted are identification with and/or relation to the terms spirituality and religion, conceived meaning of them and how "spirituality" is conceived of as expressing in daily life. Besides, an attempt is made to test Paul Heelas' wellknown thesis that a "spiritual revolution" is gradually taking place, as religion gives way to spirituality (Heelas 2002: 365). By "religion" Heelas means "obedience to a transcendent God and a tradition that mediates his authority", while he defines "spirituality" as "experience of the divine as immanent in life". Whilst the former is under threat, the latter is, according to Heelas, thriving, and is doing well both amongst those who are not involved with institutionalized religion, and within the field of traditional religion itself (Heelas 2002: 358).

Three different kinds of material are used and combined for this study. The first one is a web based questionnaire ${ }^{1}$ distributed to a representative part of the Swedish population in $2008 .^{2}$ The number of respondents to this questionnaire was 923 . As the respondents sometimes in this study are divided into smaller groups depending on the criteria sex, age and education, some of the groups become very small, and the reliability may be questioned. Keeping awareness of this fact, I think that main trends could still be tentatively detected.

The two other kinds of materials derive from a local mapping project of religion and world view that I conduct in Sweden since the year 2008. ${ }^{3}$ Dalarna is a local area in Sweden with about 270,000 inhabitants. All groups with religious social activities, or meetings with some kind of religious connotation in a broad sense (with two or more participants present) are mapped, with special focus on activities outside traditional Christianity. As part of this project, I have conducted two special studies which I will present in this paper. The first one is an interview study containing 11 interviews with well known religious actors/producers from different religious contexts in Dalarna. One of these interviews is a group interview with four women engaged in a channelling workshop, while the other 10 interviews are individual. One interview person is a priest in the Swedish Church and another one is a priest in one of the free churches in Sweden. The remaining eight persons interviewed were engaged in different layers of the alternative spiritual environment in Sweden - two persons from a UFO-association; one healer; one yoga teacher and one yoga teacher, coach and trance medium; one person engaged in the St Germain foundation; one

\footnotetext{
$1 \quad$ This survey was financed by the Swedish newspaper Dagen.

2 They were included in a pool of 200,000 people who had agreed to take part in panels by filling out questionnaires for different studies on the web. The respondents received a small gratification for their work, which meant that the falling off was very low. The argument against web based surveys is that there might be an over representation of people used to the Internet (having connotations to age, sex and education). However, the respondents seem to be well distributed according to these criteria, with, however, a slightly lower number of respondents between 45-54 years, and a slight over representation between 35-44 years.

3 I am conducting this study together with Peter Åkerbäck, Stockholm university, with support from The Swedish Research Council (Vetenskaprådet).
} 
shaman and witch; and one trance medium. An interesting fact is that three of these persons were also engaged and active in the Swedish Church. No representativity of anything has been searched - the interviews are considered as more or less random case studies. Among other questions, the interview persons were asked how they defined the concepts spirituality and religion, the relation between them and how they thought spirituality to express in daily life.

The second study derived from this project consists of a questionnaire distributed to one of the mapped groups, an evening yoga class group, with 18 respondents. Among other questions, a question about self identity relating to being religious and/or spiritual was asked, as well as open-ended questions about how they defined the concepts spirituality and religion.

Combining these three studies, a qualitative as well as a quantitative analysis was possible.

Below, I will discuss the results of these studies in the light of recent academic discussions and research relating to the concept of spirituality. I will first discuss self identification as religious or spiritual; then the definitions and relations of the concepts, and finally I will discuss the spiritual revolution thesis and make an attempt to test it on the Swedish material.

\section{Self Identification as Religious or Spiritual}

To what extent do people conceive of themselves as religious or spiritual? Several surveys indicate that many people would rather call themselves spiritual than religious, but also that there is some overlapping with some people identifying with both labels. The Internet survey in Sweden gave the following result:

Table 1. How would you label yourself? \%

\begin{tabular}{|l|l|l|l|}
\hline & All & Men & Women \\
\hline $\begin{array}{l}\text { I see myself as a religious } \\
\text { person }\end{array}$ & 5.6 & 5 & 6 \\
\hline $\begin{array}{l}\text { I see myself as a spiritual } \\
\text { person }\end{array}$ & 21.5 & 16 & 27 \\
\hline $\begin{array}{l}\text { I see myself as both } \\
\text { religious and spiritual }\end{array}$ & 10.9 & 11 & 11 \\
\hline $\begin{array}{l}\text { I see myself as neither } \\
\text { religious nor spiritual }\end{array}$ & 62 & 69 & 55 \\
\hline
\end{tabular}


In the RAMP study ${ }^{4}$ from the end of the 1990 's, questions about identifying as religious and/or spiritual were framed in other ways, so the percentages can unfortunately not be compared. Similar tendencies as in the present study could, however, be detected. Eileen Barker expresses that, while the additional use of the conception of "spirituality" does not compensate for the drop in religiosity amongst the younger generations, when used as an alternative to religiosity it exposes the existence of a statistically and socially significant way of being something other than either "religious" or secular (Barker 2008: 196).

It is evident that very few Swedes would like to call themselves only religious, but that almost one out of three would call themselves spiritual (included a certain group identifying with being both religious and spiritual). The secular tendency, as well as the tendency to identify as spiritual, is clearly related to sex. $69 \%$ of Swedish men would not identify neither with being religious, nor with being spiritual, while the figure for females is considerably less, $55 \%$. $27 \%$ of the women identify as only spiritual, with only $16 \%$ of the men doing the same. Both these tendencies are in line with findings in other studies. It is a common finding that males score higher on being secular than do women. It is also a common finding that several more women are engaged in the alternative spiritual environment than men (Frisk 2003), and that there seems to be a relation between self-identification as spiritual and engagement in the alternative subculture. A Swedish/Danish sociologist of religion, Lars Ahlin, shows that there is a relation between calling oneself a "spiritual seeker" and components in the alternative environment like belief in a spiritual power, belief in God within the human being, belief in reincarnation and a belief that there are truths in most religions (Ahlin 2005: 52-53). One reason for females being more involved in this environment than men, and also being less secular than men, may be cultural constructions of gender and historical discrimination of the female sex by the Christian church.

The questionnaire distributed to the yoga group confirms that significantly more people from the yoga practitioner group identify with being a spiritual person than a representative choice of the Swedish population, and a substantially minor portion identifies as secular oriented. Of the 18 yoga practitioners, 9 would identify as a spiritual person, 4 as both religious and spiritual, 1 as a religious person and 3 as neither religious nor spiritual. There is, thus, one more indication that identification with the spirituality concept is related to other alternative activities.

Is there a long term change as to if people identify as religious or spiritual? Lacking long term data, one way of finding out could be to look at age, as world view is often formed at a young age and more or less kept during life. This would mean that world view changes take place gradually, as different generations, with generation specific experiences, come of age (Pettersson 1988: 19-23). If more younger people than older self identify as spiritual, it might be a growing tendency:

4 "Religious and Moral Pluralism", a project carried out in 11 countries of Western and Central Europe in 1997-1999. 
Table 2. Self Identification by age. $\%$

\begin{tabular}{|l|l|l|l|l|l|l|l|l|l|l|l|}
\hline & $18-24$ & $25-29$ & $30-34$ & $35-39$ & $40-44$ & $45-49$ & $50-54$ & $55-59$ & $60-64$ & $65+$ & All \\
\hline Religious & 6 & 4 & 5 & 7 & 3 & 8 & 2 & 8 & 8 & 7 & 6 \\
\hline Spiritual & 18 & 13 & 22 & 18 & 17 & 28 & 31 & 36 & 21 & 18 & 22 \\
\hline Both & 8 & 6 & 9 & 9 & 17 & 9 & 11 & 7 & 15 & 13 & 11 \\
\hline Neither & 67 & 77 & 65 & 66 & 64 & 55 & 56 & 49 & 56 & 62 & 62 \\
\hline
\end{tabular}

Dividing the respondents in ten groups depending on age made some of the groups very small. The groups contained between 44-130 persons each, with the smallest group being the one between 50-54 years. The tendencies could, however, still be interpreted with some reliance. And as we see, in the Swedish survey material there is no clear tendency that the younger generations would consider themselves more spiritual than the older generations do. A tendency that younger people are even more secular minded than older people may be tracked, as well as a middle age bulk as to the tendency to self identify as spiritual. This is the generation born after World War 2, sometimes called "the baby boom generation" (Roof 1993). Putting together the group that self identify as only spiritual, and the group that self identify as both religious and spiritual, the result comes out even clearer:

Table 3. Self Identification as spiritual by age. $\%$

\begin{tabular}{|l|l|l|l|l|l|l|l|l|l|l|l|}
\hline & $18-24$ & $25-29$ & $30-34$ & $35-39$ & $40-44$ & $45-49$ & $50-54$ & $55-59$ & $60-64$ & $65+$ & All \\
\hline $\begin{array}{l}\text { Both } \\
\text { spiritual } \\
\text { and } \\
\text { spiritual } \\
\text { religious }\end{array}$ & 26 & 19 & 31 & 27 & 34 & 37 & 42 & 43 & 36 & 31 & 33 \\
\hline
\end{tabular}

Thus no tendency could be traced to show that self identification as spiritual is becoming more common in Sweden with younger generations.

A cross-tabulation with levels of education was also attempted. Concerning the relation between higher education and identification with spirituality the picture was diffuse, with the lowest educated and the highest educated scoring a little lower on self identification as spiritual than average, and the middle educated a little higher. The differences, however, were small. 


\section{Spirituality and religion}

What then, do people mean by spirituality and religion respectively?

In academic discussions, "spirituality" is often presented as being a more personal and individual concept than "religion" (King 2001: 5-9, Roof et al. 1995: 247-252, Barker 2004a; Hanegraaff 2005), more focused on the human being than on supernatural beings (King 2001: 5-9, Barker 2004a), syncretistic and pluralistic (Roof et al. 1995: 247-252, Barker 2004a), anti-hierarchical (Roof et al. 1995: 247-252, Barker 2004a) and innerworldly (Barker 2004a).

As to the relation between spirituality and religion, Eileen Barker presents some logical possibilities. First, the two concepts could be completely interchangeable. Secondly, spirituality could be seen as one or more sub-divisions of religiosity, or even the very core of religiosity. A third conception is that religiosity is a subsection of spirituality, where spirituality for example could be interpreted as embracing all aspects of life. Fourthly, religion and spirituality could be entirely different phenomena. And, finally, the two concepts could overlap, sharing some characteristics but not others (Barker 2008: 190-191).

Judging from the interviews in the Swedish study, it is clear that the concept "spirituality" could be used in many different ways. The priest from the free church gives the most different answer compared to the others, saying that God is spirit, and to communicate with God you have to use your own spirit, but he also comments that God is personal and that the emphasis should always be on God, not on the human individual. Most of the others in the interview material seem to conceive of spirituality and religion as partly overlapping, while in the yoga group the main conception seems to be that religion and spirituality are opposites to each other. The priest in the Swedish Church is (not surprisingly) more positive to religion than most of the others, and emphasizes that religion and spirituality complement each other. He conceives of spirituality as relating to personal experience, while religion is the structured, reflected and commented experience of God. He thus considers the spiritual experience as primary and religion as secondary. Both religion and spirituality are, however, in his opinion, necessary. According to the priest, divine service in church is a natural arena for the primary spiritual experience.

Several of the other interview persons claim that spirituality could well be practiced in religious contexts, and that the essence in religion is constructive and based on spirituality, but still talk about religion mostly in a negative way. Several mention that religion could lead to war, that religion puts God in a box, has a strange and complicated organization, and represents power struggles, laws, rules and hierarchies. Some answers implicate the opinion that religion was once up on a time a good thing, but that it has developed in wrong directions over time. From the yoga group, several answers, besides connecting religion with judgment, power struggles and rules, also connected religion to "groups" and "teachings".

Two interview persons, and almost all respondents from the yoga group, talk about religion as the opposite to spirituality. One respondent says, for example, that religion 
means to bend before something outside oneself, while spirituality is to see the divine within yourself. Another respondent says that religion is based on fear, while spirituality is based on love. Two (female) respondents from the yoga group say that religion expresses male authority. Altogether thirteen respondents from the yoga group answered the open-ended question asking about similarities and differences between religion and spirituality. Only one of these responded with similarities, while all the others responded with only differences, also an indication of the conceived difference between the two concepts.

One respondent in the interview material speaks about spirituality as a continuation of religion for the individual who wants to develop spiritually. He compares religion with the primary school and spirituality with the university. This respondent frames it that people who are like small children need the church or the mosque, but as you become more mature you do not need religion any more. This, of course, is another way of expressing the inferiority of religion and superiority of spirituality.

Spirituality is defined in both groups as: inner experience (stressed by many), something very personal and individual, love, the divine within, contact with your own essence or higher self, or as intuition. Especially the yoga practitioners emphasized that spirituality is something very personal and inside every individual.

The question about how spirituality was practiced in everyday life was answered in several different ways. From the interview group - where there were some people also engaged in the church - some respondents say that spirituality could be practiced in church. This kind of answer was absent in the yoga group. In the yoga group many respondents answered that spirituality is practiced in yoga, meditation and healing. Both groups gave answers like that spirituality could be practiced by being present or always being in contact with your higher self or by listening to your heart; or by creative activities like music and art; or being in nature or being alone; and - to me most surprisingly - in both groups several respondents answered that spirituality could be practiced by helping other people, seeing everyone's equal value and act accordingly, and by meeting others with empathy and love. Thus there also seems to be an ethic aspect of spirituality. In the interview group there were also some respondents claiming they practiced spirituality by taking a hot bath or patting the cat, that is activities that might be thought to be very secular or at least inner-worldly.

Summarily, spirituality seems to mean very different things to different people. Some answers keep returning, however, especially answers in the direction that spirituality is connected to inner, personal experiences. The relationship between spirituality and religion is also conceived of in different ways. Quite often, however, spirituality is constructed and represented in opposition to religion, with spirituality representing all positive aspects and religion all negative aspects. One interesting finding was, however, that some people in the interview material were engaged both in the church and in the alternative environment. It raises the question if borders between different kinds of religiosity might slowly be disappearing, with participants having an individual agenda and a focus on personal experience more than ideological differences. This orientation might open the possibility to attend environments with different world view ideologies without being disturbed. Spirituality 
seems to be conceived of as practiced in some different ways: surely connected to some "practices" like yoga, meditation, healing, prayer and divine service; but also by simply "being" or "listening to your heart"; and also in quite mundane activities as being in nature, walking or taking a bath. Spirituality seems to be conceived of as involving several different aspects of "being human"; relating to identity, focus, attitude, emotions and ethics.

Compared to the academic understanding of spirituality as personal and individual, focused on human being and being syncretistic and pluralistic, anti-hierarchical and innerworldly, my studies essentially agree with this understanding. However, in my material it is mostly emphasized that spirituality relates to a personal and individual experience, that it relates to the inner self rather than to a supernatural being "out there", and that it can be experienced not only in contexts like meditation or divine service, but also in nature, music, a hot bath or by meeting others with love - which would correlate with "innerworldliness". Less emphasized is the syncretism, which, however, may be implicit and more evident seen from outside, and the anti-hierarchical aspect, which also may be implicit in the individual focus.

\section{A Spiritual Revolution?}

Paul Heelas suggests that a spiritual revolution is gradually taking place, as religion gives way to spirituality (Heelas 2002: 365). How can you test this suggestion?

There are obviously several ways to test this thesis. Heelas \& Woodhead suggest in their book The Spiritual Revolution (2005) that congregational church activities should be seen as mainly "religious", while "holistic" (or alternative, or New Age) activities should be seen as mainly "spiritual". The religious forms of the sacred, according to Heelas \& Woodhead, emphasize a transcendent source of significance and authority to which individuals must conform, while the spiritual forms of the sacred emphasize inner sources of significance and authority and the cultivation or sacralization of unique subjective-lives (2005: 6-13). Heelas \& Woodhead counted in their study how many people were active in the congregational environment and the holistic environment respectively in the small town Kendal in Britain. The result was, in short, that many more people were engaged in the congregational environment than in the holistic environment, but that, compared in a longitudinal perspective, participation in the holistic activities might be rising and participation in the congregational activities falling. That is, in the long run a "spiritual revolution" may be expected (Heelas \& Woodhead 2005).

Another possibility to test the thesis of the spiritual revolution, to my knowledge not yet attempted, is to operationalize the concept of spirituality into a set of attitudes, and test how they score in a representative sample of a population. This method would measure another dimension than the method used by Heelas \&Woodhead: while they used participation in meetings/services as the main criteria, my method would measure individual attitudes. One advantage of my method is also that it does not differ between congregational 
environments and holistic environments as more or less automatically being religious and spiritual respectively (even though this matter is also problematized by Heelas \& Woodhead).

Deciding to try this new road, the first challenge was how to operationalize the concept of spirituality. The academic understanding of spirituality is, as we have seen, focused around some central aspects: emphasis on personal experience at the expense of ideology or dogma; self-spirituality or a shift from God to human being; eclecticism and syncretism; radical egalitarianism or recognizing each person as his/her own spiritual authority; and this-worldliness rather than emphasizing life after death. Focusing on these concepts, I tried to construct some attitude items implicating spirituality, and included them in the Internet questionnaire of 2008 :

"All religions have a certain truth"

"I like to use several religious teachings as a resource when I create my own world view"

"Different religious beliefs and organizational belongings are not so important, the important thing is the inner spiritual experience"

"The divine could be experienced for example in nature, in love and sex"

"The body and thereby health is important to reach spiritual harmony" 5

These items were mixed with other items measuring other kinds of attitudes and beliefs. The respondents were asked to agree completely, agree partly, disagree partly or disagree completely with the different claims.

Table 3. Attitudes relating to spirituality. \%

\begin{tabular}{|l|l|l|l|l|}
\hline & Agree completely & Agree partly & Disagree partly & Disagree completely \\
\hline All religions true & 19.3 & 40.5 & 22.1 & 18.2 \\
\hline $\begin{array}{l}\text { Create own world } \\
\text { view }\end{array}$ & 8.7 & 21.8 & 23.5 & 46 \\
\hline $\begin{array}{l}\text { Inner spiritual } \\
\text { experience }\end{array}$ & 26.9 & 39 & 16.3 & 17.7 \\
\hline
\end{tabular}

$5 \quad$ It is easy to be afterwise when constructing and using questionnaire items. In retrospect, I realize that I tried to cover too many areas in each item, and that I should have separated the different parts of the constructed claims. If there had been more space in the study, of course there should also have been several slightly different items testing each attitude. This study must therefore be seen as very preliminary, pointing to some directions, but more detailed studies should be done to confirm or disconfirm the tentative results. 


\begin{tabular}{|l|l|l|l|l|}
$\begin{array}{l}\text { Divine in nature, } \\
\text { love, sex }\end{array}$ & 28.1 & 39.1 & 13.9 & 18.9 \\
\hline $\begin{array}{l}\text { Body and health } \\
\text { spiritual }\end{array}$ & 34 & 41.4 & 12.5 & 12.1 \\
\hline
\end{tabular}

Adding together the agree-completely and the agree-partly answers, four of the items add up to between $60-75 \%$ of the respondents agreeing. The fifth item, "I like to use several religious teachings as a resource when I create my own world view", adds up to (comparatively) only $30 \%$ of the respondents agreeing. As a comparison, corresponding percentage for agreeing on belief in reincarnation was $33 \%^{6}$, that it is possible to contact dead people $35 \%$, and belief in astrology $22 \%$. Four of the items constructed to measure spirituality thus showed comparatively very high percentages, with a majority of Swedish people agreeing (at least partly) with them.

Then what about the item, meant to measure eclecticism, to which only half or less than half of the percentage agreeing on the other four items, agreed? Speculating, the specific wording of the item might have been problematic for some people, as it included the concept "religious teachings". Rethinking the formulation, as spirituality is centred on experience and averse to ideology, probably the wording "religions teachings" was not a good choice to use in this context, if spirituality was the target.

However, a majority of Swedish people, up to three thirds, agree (at least partly) on the other four of these items meant to measure spirituality. In the following, we will concentrate on these four items. If we conclude that these items really measure orientations towards spirituality, then spirituality could be considered a wide spread phenomenon in Sweden.

Is there any way, then, to investigate if it is an increasing tendency, if we could say that a "spiritual revolution", in the sense of Paul Heelas and Linda Woodhead, is gradually happening? Cross-tabulating the result with the different age groups, the results are as follows:

\footnotetext{
$6 \quad$ This is a high percentage according to Swedish standards. The normal percentage on this item should be expected to be just over $20 \%$. I have no explanation as to the high rate on this item in this study. It is the only item scoring unexpectedly high.
} 
Table 4. Attitudes relating to spirituality divided to age groups. \%

\begin{tabular}{|l|l|l|l|l|l|l|l|l|l|l|l|}
\hline & $18-24$ & $25-29$ & $30-34$ & $35-39$ & $40-44$ & $45-49$ & $50-54$ & $55-59$ & $60-64$ & $65+$ & All \\
\hline $\begin{array}{l}\text { All } \\
\text { religions } \\
\text { true }\end{array}$ & 55 & 50 & 59 & 63 & 60 & 70 & 58 & 58 & 62 & 62 & 60 \\
\hline $\begin{array}{l}\text { Inner } \\
\text { spiritual } \\
\text { experience }\end{array}$ & 61 & 59 & 67 & 65 & 65 & 66 & 80 & 71 & 66 & 67 & 66 \\
\hline $\begin{array}{l}\text { Divine in } \\
\text { nature, } \\
\text { love, sex }\end{array}$ & 52 & 61 & 70 & 63 & 70 & 77 & 75 & 68 & 73 & 69 & 67 \\
\hline $\begin{array}{l}\text { Body and } \\
\text { health } \\
\text { spiritual }\end{array}$ & 66 & 71 & 78 & 74 & 75 & 76 & 85 & 82 & 79 & 78 & 75 \\
\hline
\end{tabular}

Our expected result, if spirituality is an increasing orientation among Swedish people, would be that these attitudes would be more common among younger generations. On the contrary, as we can see, the result rather supports an increasing spiritual orientation with older age.

Self identification as spiritual also had a gender difference, as it was much more common among females. I therefore also divided the result according to sex:

Table 5. Attitudes relating to spirituality divided by sex. \%

\begin{tabular}{|l|l|l|}
\hline & Woman & Men \\
\hline All religions true & 63 & 57 \\
\hline Inner spiritual experience & 69 & 63 \\
\hline Divine in nature, love, sex & 68 & 66 \\
\hline Body and health spiritual & 80 & 71 \\
\hline
\end{tabular}

There is a slight overrepresentation by females on all these items, but far from the gender differences common to most items related to the New Age. For example, according to the same study, $43 \%$ of women believed in reincarnation, compared to $23 \%$ of men. $50 \%$ of the 
women believed in the possibility to contact dead people, but only $21 \%$ of the men. $32 \%$ of the women believed in astrology, but only $12 \%$ of the men. The spiritual orientation measured by these items thus seems to be much more independent of gender than both New Age orientation and self identification as spiritual. That means, to call oneself spiritual is more common among females than among males; but if you try to operationalize what spirituality means, then the differences decrease radically.

The results were also divided as to level of education:

Table 6. Attitudes relating to spirituality divided by education. $\%$

\begin{tabular}{|l|l|l|l|l|l|}
\hline & Grammar school & High school & University -3 yrs & University +3 yrs & All \\
\hline All religions true & 45 & 62 & 65 & 59 & 60 \\
\hline $\begin{array}{l}\text { Inner spiritual } \\
\text { experience }\end{array}$ & 56 & 62 & 72 & 70 & 66 \\
\hline $\begin{array}{l}\text { Divine in nature, } \\
\text { love, sex }\end{array}$ & 62 & 66 & 69 & 68 & 67 \\
\hline $\begin{array}{l}\text { Body and health } \\
\text { spiritual }\end{array}$ & 70 & 70 & 78 & 86 & 75 \\
\hline
\end{tabular}

Another interesting tendency comes out - although not very strong - that agreeing with the spirituality items increases with further education. Compared to some of the New Age-related items, the contrast is clear. Belief in reincarnation, belief in the possibility to contact dead people, and belief in astrology are beliefs that decrease with education.

Finally, I cross-tabulated the respondents in the study who believed in reincarnation - 289 persons - a group that I call "New Age light" as almost everyone in the New Age environment believes in reincarnation (see Frisk 2003) with the spirituality items. Again, the group is very small, but tendencies may be tentatively detected:

Table 7: Attitudes relating to spirituality related to belief in reincarnation. $\%$

\begin{tabular}{|l|l|l|}
\hline & All agree & Reincarnation-believers agree \\
\hline All religions true & 59.8 & 73.6 \\
\hline Inner spiritual experience & 65.9 & 80.3 \\
\hline
\end{tabular}




\begin{tabular}{|l|l|l|} 
Divine in nature, love, sex & 67.2 & 84.2 \\
\hline Body and health spiritual & 75.4 & 86.5 \\
\hline
\end{tabular}

There is thus a relation that reincarnation believers score higher on the spirituality items than other people. Many people, however, score high on these items although not being reincarnation believers.

Thus the above results may indicate that orientation towards spirituality is partly related to the holistic environment, but is also partly independent of and developing outside it. That is, spiritual orientation is more common among people engaged in the holistic environment than among other people, but is still quite common also among people not engaged in this environment. The rates of the spirituality items do not tend to increase with younger generations, thus disconfirming the thesis that younger people are more involved with spirituality than older people. But there is, on the other hand, a slight increase of spiritual orientation related to higher education. This may mean that the spiritual revolution thesis may be right in that there is an attitude change cutting through the whole world view environment - not restricted to the New Age - but that it is related not to younger generations coming of age in the first place, but rather (however somewhat weakly) related to higher education. And, if the level of education continues to rise, spiritual orientations might be increasing in the future.

\section{Conclusion}

Spirituality is a term identified with and used by a substantial portion of the Swedish population. Operationalized into attitude items, around two thirds of the Swedish population agree at least partly with the four items used in this study. The spirituality orientation, measured in this way, seems to be much more widespread than New Age items such as belief in reincarnation or belief in astrology, and also less related to gender. There is also, however, a relation to the holistic environment in that believers in reincarnation score higher on the spirituality items than others.

Asked what respondents mean by the term spirituality, it becomes clear that spirituality could mean very different things for different people. Often, in the material used in this study which mainly derived from holistic environments, there is an emphasis that spirituality is something very personal and connected to the experiential dimension.

Spirituality was conceived of by different respondents as having different relations to the concept of religion, but was quite often constructed either as overlapping with religion or in opposition to religion. A common discourse represents spirituality as indicating positive values and religion as indicating negative values.

Spirituality was also said to be expressed in everyday life in very different ways. Some people claim to express spirituality in congregational service, some people in holistic 
activities (and some people in both, which may indicate a blurring of borders between different kind of religiosity), but spirituality is clearly also conceived of as being expressed in personal focus or perspective, as "being present" or "being in contact with your higher self". Spirituality also could have en ethical dimension, in meeting other people with empathy and love. Spirituality also had innerworldly dimensions, being experienced in walking in nature or taking a bath.

Is there a "spiritual revolution" taking place? Looking at age spectra, this thesis could not be confirmed in this material. However, there are indications that agreeing with spirituality oriented items is related to higher education. So, If education level increases, then also spiritual attitudes may be expected to increase.

Then why is the spiritual revolution taking place, and how could it be related to higher education? According to Heelas \& Woodhead (2005: 2-4) the spiritual revolution takes place because of the subjective turn of modern culture, a turn away from life lived in terms of external or "objective" roles, duties and obligations, and a turn towards life lived by reference to one's own subjective experiences. This is also a turn away from outer authority, as the individual becomes his or her own authority. In other words, the spiritual revolution is connected to the individualism spreading in all contexts in our culture.

Frisk (2011, forthcoming) suggests that the spirituality paradigm shift is related to globalization. With the contemporary continually denser communication, all kinds of beliefs and religious elements, from all parts of the world, are co-existing in one and the same place, in a way historically unknown. This offers the individual an innumerable selection of world view elements, and also exposes the individual to relativization, undermining all absolute truth claims. Realizing the relativization of himself and his own beliefs in a global context, the individual tends to turn away from ideological dimensions, instead emphasizing his own personal experience and his own choice of different world view elements. Thus globalization reinforces the cultural individualism noticed by Heelas \& Woodhead. And, with further education, more people might be more exposed to globalizing tendencies. This may be the explanation behind the possible spiritual paradigm shift discussed in this paper.

\section{REFERENCES}

\section{Printed material}

Ahlin, Lars. 2005. Pilgrim, turist eller flykting? En studie av individuell religiös rörlighet iI senmoderniteten. Stockholm/Stehag: Symposion.

Barker, Eileen. 2008. "The Church Without and the God Within: Religiosity and/or Spirituality?" Pp. 187-202 in The Centrality of Religion in Social Life: Essays in Honour of James A. Beckford, edited by Eileen Barker. Aldershot: Ashgate.

Frisk, Liselotte. 2003. "New Age Participants in Sweden: Background, Beliefs, Engagement and 'Conversion'", in New Religions in a Postmodern World, edited by Mikael Rothstein and 
Reender Kranenborg. Aarhus: Aarhus University Press.

Frisk, Liselotte. 2011, forthcoming. "Globalization: An Important Key Factor in Contemporary Religious Change." JASANAS (London: Alternative Spiritualities and New Age Studies Association).

Hanegraaff, Wouter. 2005. "Spectral Evidence of New Age Religion: On the substance of ghosts and the use of concepts." JASANAS (London: Alternative Spiritualities and New Age Studies Association). Pp. 35-58.

Heelas, Paul. 2002. "The Spiritual Revolution: From "Religion” to "Spirituality", Pp. 357378 in Religions in the Modern World, edited by Linda Woodhead et al. London and New York: Routledge.

Heelas, Paul and Linda Woodhead. 2005. The Spiritual Revolution: Why Religion is Giving Way to Spirituality. Oxford: Blackwell Publishing.

King, Ursula, ed. 2001. Spirituality and Society in the New Millennium. Brighton/Portland: Sussex Academic Press.

Pettersson, Thorleif. 1988. Bakom dubbla lås. En studie av små och långsamma värderingsförändringar. Stockholm: Institutet för framtidsstudier.

Roof, Wade Clark. 1993. A Generation of Seekers: The Spiritual Journeys of the Baby Boom Generation. San Francisco: Harper San Francisco.

Roof, Wade Clark, Jackson W. Carroll and David A. Roozen. 1995. The Post-War Generation and Establishment Religion: Cross-Cultural Perspectives. Boulder, San Francisco, Oxford: Westview Press.

\section{Unprinted material}

Internet survey 2008, conducted by Dagen. 
